\section{PRÁTICAS CORPORAIS E PAULO FREIRE: UMA ANÁLISE SOBRE A PRODUÇÃO DO CONHECIMENTO}

\author{
BODILY PRACTICES AND PAULO FREIRE: AN ANALYSIS OF KNOWLEDGE
}

PRÁCTICAS CORPORALES Y PAULO FREIRE: UN ANÁLISIS SOBRE LA PRODUCCIÓN DEL CONOCIMIENTO

\author{
Valdilene Aline Nogueira*, Daniel Teixeira Maldonado**, \\ Sheila Aparecida Pereira dos Santos Silva*, Elisabete dos Santos Freire*, \\ Maria Luiza de Jesus Miranda*
}

\begin{abstract}
Palavras chave: Educação popular. Educação Física. Empoderamento Teoria Crítica.

Resumo: 0 objetivo deste estudo é entender como a teoria freireana vem sendo estudada pela comunidade acadêmica da Educação Física (EF). Realizou-se uma revisão sistemática nas bases de dados ERIC, SPORTDiscus e Fuente Académica, utilizando os descritores Empoderamento; Teoria Crítica e Paulo Freire combinados com Educação Física, em inglês e português. Foram selecionados os estudos que dissertavam sobre danças, lutas, ginásticas, esportes, jogos, brincadeiras e/ou atividades rítmicas e expressivas. Organizou-se o mapeamento da produção de conhecimento e a discussão das categorias Consciência; Cultura Popular; e Empoderamento. Percebeu-se que raros são os estudos realizados na EF que se fundamentam na perspectiva freireana. Contudo, os estudos encontrados evidenciam a contribuição dos ensinamentos de Freire para a efetivação de uma EF mais crítica e democrática. Portanto, novas investigações devem aprofundar as relações entre a teoria proposta pelo autor e a EF.
\end{abstract}

\section{Keywords:}

Popular Education.

Physical Education.

Empowerment.

Critical Theory.

Abstract: This study aims at understanding how Freirean theory has been studied by the Physical Education (PE) academic community. A systematic review was carried out in the databases ERIC, SPORTDiscus, and Fuente Académica, with the following descriptors; Empowerment; Critical Theory; and Paulo Freire, combined with Physical Education both in English and Portuguese. Studies about dance, fight, gymnastics, sports, games, games, and/or rhythmic and expressive activities were selected for analysis. Knowledge production and the discussion were mapped for the following categories: Consciousness; Popular culture; and Empowerment. Freirean studies are rare in PE. However, those found show the contribution of Freire's teachings to a more critical and democratic PE. Therefore, new investigations must further examine Freirean theory and PE.

Palabras clave: Educación Popular Educación Física. Empoderamiento. Teoría Crítica.
Resumen: El objetivo de este estudio es entender cómo la teoría freireana viene siendo estudiada por la comunidad académica de Educación Física (EF). Se realizó una revisión sistemática en las bases de datos: ERIC, SPORTDiscus y Fuente Académica, utilizando los descriptores Empoderamiento, Teoría Crítica y Paulo Freire combinados con Educación Física, en inglés y en portugués. Se seleccionaron estudios que versaban sobre danzas, luchas, gimnasias, deportes, juegos y actividades rítmicas y expresivas. Se organizó el mapeo de la producción de conocimiento y la discusión de las categorías Consciencia, Cultura Popular y Empoderamiento. Se percibió que raros son los estudios realizados en la EF que se fundamentan en la perspectiva freireana. Sin embargo, los estudios encontrados evidencian la contribución de las enseñanzas de Freire para la constitución de una EF más crítica y democrática. Por lo tanto, nuevas investigaciones deben profundizar las relaciones entre la teoría propuesta por el autor y la EF.
* Universidade São Judas Tadeu. São Paulo, SP, Brasil.

E-mail: valdilenenogueira@yahoo. com.br; sheila.silva@uol.com.br; elisabetefreire@uol.com.br; prof.mlmiranda@usjt.br

** Instituto Federal de Educação, Ciência e Tecnologia de São Paulo. São Paulo, SP, Brasil. E-mail: danieltmaldonado@yahoo. com.br

Recebido em: 20/07/2018 Aprovado em: 03/12/2018

DOI: hitps://doi.org/10.22456/1982-8918.85020 (c) (1) () Licence 


\section{INTRODUÇÃO}

Partindo da visão dialética e influenciado pelo pensamento marxista, Paulo Freire desenvolveu sua compreensão acerca de uma Educação Libertadora, que tem como contexto a relação ser humano/sociedade, ambos inacabados. As ideias do autor solidificam no cenário educacional o entendimento sobre o qual nós, seres também inacabados, na constante busca de "sermos mais", influenciamos e transformamos a realidade objetiva a nossa volta, ao passo que os efeitos desta transformação se refletem em nosso próprio cotidiano (FISCHMAN, 2011).

Paulo Freire é um dos principais autores da Pedagogia e ainda hoje seus escritos inspiram professores e propostas educacionais no mundo todo, tendo influência também na EF. Esta inspiração pode ser percebida principalmente quando se trata das questões de empoderamento, consciência, cultura popular e libertação de todas as formas de opressão e de dominação cultural, descritas e combatidas nos mais diversos contextos (APPLE; AU; GANDIN, 2011; SPAAIJ; JEANES, 2013). Por essa razão, Paulo Freire (1996) salienta que será pelo aprofundamento da consciência crítica que nós, enquanto seres humanos que somos, conscientizaremos da realidade, para então transformá-la.

Sabe-se que uma das mais conhecidas obras de Paulo Freire é Pedagogia do Oprimido, livro publicado pela primeira vez em espanhol e inglês e que chegaria ao Brasil tardiamente, em função da Ditadura Militar e da censura imposta. Nesta e nas outras obras que escreveu, Paulo Freire defende um sistema de educação que enfatiza o aprendizado como uma ação de coragem e liberdade (GADOTTI, 1996; FISCHMAN, 2011; VALOURA, 2006).

A partir dessa perspectiva, chamam atenção alguns conceitos desenvolvidos pelo educador, como: "Educação Bancária", na qual professores preenchem os educandos passivos com informações; "Cultura do Silêncio", em que pessoas dominadas são silenciadas por conta da imposição cultural de quem as domina; e "Empoderamento", no qual os sujeitos dominados tomam o poder para si, a partir do desenvolvimento da consciência crítica (FREIRE, 1987; VALOURA, 2006).

Em relação a este último conceito, embora a palavra Empowerment já existisse na língua inglesa, significando dar poder a alguém para realizar uma tarefa sem precisar da permissão de outras pessoas, o conceito de Empoderamento em Paulo Freire segue uma lógica diferente. Para o educador, a pessoa, o grupo ou a instituição empoderada "é aquela que realiza, por si mesma, as mudanças e ações que a levam a evoluir e se libertar" (VALOURA 2006, p. 3).

Assim, a obra de Paulo Freire nos ensina que os educadores precisam se assumir como animadores culturais, aprendendo a abdicar de preconceitos ou de conclusões fatalistas a respeito dos educandos. Em uma prática verdadeiramente democrática é importante que não exista "invasão cultural" e ao educador cabe deixar-se envolver dialogicamente no mundo criado a partir dos diversos contextos alimentados pelo grupo (FREIRE, 1987). Nas palavras de Paulo Freire, ao trabalhar no Círculo de Cultura, por exemplo, sem intenção de demarcar qual cultura é mais importante do que a outra, o educando descobriria que "[...] cultura é a poesia dos poetas letrados do seu país, como também a poesia do seu cancioneiro popular. Que cultura são as formas de comportar-se" (FREIRE, 1963, p. 17). 
Influenciadas por esses ideais, a partir da década de 1980 acirram-se as discussões epistemológicas em torno do corpo, da cultura e do movimento. No Brasil, esses debates objetivaram na EF o estabelecimento de novos percursos pedagógicos frente à escola que seria construída no processo de redemocratização do país. As influências históricas construídas até então não são desconsideradas, mas a partir do Movimento Renovador/Progressista as reflexões começam a ultrapassar uma visão biologizante do componente curricular e apresentam novas propostas pedagógicas para a área (BRACHT, 1999; CASTELLANI FILHO, 1988).

Essas mudanças epistemológicas apontam para transformações nas concepções de objeto e objetivo da EF brasileira, e entendem as práticas corporais a partir da valorização e da tematização do mundo dos alunos, estabelecendo, assim, uma relação com a realidade extraescolar que advoga por uma metodologia dialógico-problematizadora. Evidencia-se, pois, a importância pedagógica das culturas tradicionais próprias do "se-movimentar", bem como a participação do aluno nas decisões do ensino, visando ao desenvolvimento da criticidade acerca das manifestações da cultura corporal (BRACHT, 2017; KUNZ, 1994; SOARES et al., 2012).

Entende-se que a partir da vivência e da interpretação das práticas corporais os seres humanos produzam a linguagem corporal, que possibilita aos indivíduos interagir entre si, comunicando-se e transformando-se por seu tocante expressivo. Logo, ao brincar, dançar, lutar, fazer ginástica e praticar esportes, a sociedade se apropria, ao passo que também transforma em uma relação dialética o repertório gestual que caracteriza a cultura corporal do cenário que se articula à sua volta (NEIRA, 2016).

Amparados por essas reflexões, encontramos diversas aproximações do pensamento de autores do Currículo Crítico da Educação que permeiam tais discussões na EF. Rocha et al. (2015) realizaram um estudo que objetivou analisar quais e como as teorias curriculares têm subsidiado os estudos na EF no cenário das produções acadêmicas brasileiras. A análise sistemática realizada por esses autores indica que, dos 35 artigos selecionados, $74 \%$ tinham como referencial teórico os autores das bases críticas da Educação, destacando-se Demerval Saviani, José Carlos Libâneo, Michael Apple, Ivor Goodson e Michael Young.

Não desconsiderando a influência desses autores citados para a organização que a EF vem assumindo no Brasil, causa-nos inquietação entender qual espaço do educador Paulo Freire nesse contexto. Vista a importância de Paulo Freire, patrono da Educação Brasileira e autor com mais citações na área educacional em todo mundo, torna-se relevante entender como a EF vem produzindo conhecimentos que se relacionem com o educador (BOSSLE, 2018).

Embora o impacto da obra de Paulo Freire seja evidente, a contribuição do autor na produção do conhecimento científico tem sido pouco investigada (GERBASI, 2013). Assim, neste estudo nos esforçamos para aproximar nossos olhares sobre as práticas corporais da pedagogia de Paulo Freire, objetivando entender como a teoria freireana vem sendo estudada pela comunidade acadêmica da EF. A partir desse entendimento, elaboramos uma síntese do conhecimento produzido por pesquisadores que se inspiraram nos escritos do autor para discorrerem sobre assuntos, contextos e cenários que envolvem as práticas corporais. 


\section{MÉTODO}

A Revisão Bibliográfica Sistemática foi o caminho metodológico escolhido, pois ela se apresenta como uma alternativa viável para que um assunto seja investigado de maneira linear nas fontes escolhidas (GIL, 2007). Busca-se nesse tipo de estudo alcançar maior abrangência nas averiguações e nos resultados da pesquisa bibliográfica, e, por consequência, proporcionar uma maior compreensão do "estado da arte", ou seja, do que foi produzido e publicado sobre um determinado assunto a ser pesquisado. Para garantir a reprodutibilidade da pesquisa, bem como o necessário rigor metodológico, é necessário adotar um procedimento, elaborado a partir de um conjunto de passos, técnicas e ferramentas específicas (LEVY; ELLIS, 2006).

A Revisão Bibliográfica Sistemática é uma ferramenta para mapear e analisar trabalhos publicados em determinados temas de pesquisa específicos; ela é relevante pois permite ao pesquisador ou à pesquisadora realizar uma síntese do conhecimento produzido sobre o tema que se propõe melhor compreender (LEVY; ELLIS, 2006). Assim, como Freire e Miranda (2014), realizamos um levantamento dos trabalhos científicos presentes nas bases de dados do Centro de Recursos Educativos da Informação (ERIC), SPORTDiscus e Fuente Académica, do período de 1990 até 2017. A base ERIC foi escolhida por ter como foco a pesquisa educacional, área que foi amplamente analisada na obra de Paulo Freire. Em SPORTDiscus, buscamos acesso a pesquisas relacionadas, especificamente, à EF e ao Esporte. Como explicam Freire e Miranda (2014), essas duas bases têm sido utilizadas com frequência em estudos de revisão relacionados à EF. A base de dados Fuente Académica, por sua vez, tem como vantagem a inclusão de estudos internacionais em língua portuguesa e espanhola, o que pode ampliar o acesso a estudos sobre a temática investigada. Ao optar pela análise da publicação disseminada nessas três bases de dados, nossa intenção é apresentar um panorama da temática analisada, entendendo as limitações deste estudo que investiga parte de um universo maior.

O recorte de tempo escolhido se deu pelo marco histórico da redemocratização do Brasil, contexto em que as obras de Paulo Freire aprofundam as discussões acadêmicas e influenciam as Teorias Críticas no cenário mundial. Nessa fase, acontece também 0 Movimento Renovador/Progressista da EF (BRACHT, 1999).

Para realizar a pesquisa, utilizamos palavras-chave, combinadas com os operadores booleanos, organizando-as nas seguintes sentenças: (Teoria Crítica) AND (Educação Física) AND (Freire) e; (Empoderamento) AND (Educação Física) AND (Freire). As buscas foram efetuadas com os descritores nas línguas portuguesa e inglesa, realizadas por dois pesquisadores e acompanhadas por outras três pesquisadoras para garantir a fidedignidade da pesquisa.

Inicialmente, analisamos títulos e resumos de todos os artigos encontrados. A partir dessa leitura, selecionamos os artigos que abordavam a EF e/ou práticas corporais - danças, lutas, ginásticas, esportes, jogos, brincadeiras e/ou atividades rítmicas e expressivas - e que adotassem como referencial teórico a obra de Paulo Freire. Foram excluídos da análise os artigos que não apresentavam contribuições para o contexto pedagógico e/ou escolar e que não estavam disponíveis na versão completa. Após a seleção inicial, realizamos a leitura na íntegra de 35 estudos, o que resultou na identificação de 19 artigos (Quadro 1) que atendiam aos critérios estabelecidos. 
Tabela 1- Buscas nas Bases de Dados

\begin{tabular}{ccc}
\hline Base de dados & Total de artigos na busca & Artigos selecionados \\
\hline FUENTE ACADÉMICA & 295 & 9 \\
ERIC & 121 & 8 \\
SPORTDiscus & 7 & 2 \\
\hline
\end{tabular}

Total de artigos analisados: 19

Fonte: Os autores

Assim, percebemos indícios de algumas das discussões defendidas por Paulo Freire, tendo como base as obras Educação como prática da liberdade (FREIRE, 1967), Pedagogia do Oprimido (FREIRE, 1987) e Pedagogia da autonomia: saberes necessários à prática docente (FREIRE, 1996). Nesse contexto, definimos como categorias de discussão que serão a fonte da síntese realizada: Consciência; Cultura Popular e Empoderamento, de acordo com a similaridade temática e a consonância com as obras de Paulo Freire (SALDAÑA, 2013).

Essas temáticas foram trabalhadas por Paulo Freire de maneira densa no decorrer de sua obra e apresentam a face marcante de um educador que fez do desenvolvimento da consciência crítica uma estratégia política de emancipação de um povo que, consciente de seu estado de opressão, poderia lutar por melhores condições de vida, ao passo do reconhecimento de que sua cultura é tão importante quanto qualquer outra cultura (GADOTTI, 1996).

Assim, na categoria Consciência foram discutidos os trabalhos que apresentaram reflexões que relacionavam as práticas corporais à reflexão social, à mídia, à política e aos contextos sociais em ocorriam ou se manifestavam. Já a discussão na categoria Cultura Popular foi realizada evidenciando reflexões sobre as práticas corporais e os aspectos regionais e culturais de diversas populações. Nas reflexões sobre a categoria Empoderamento, analisamos como as práticas corporais são percebidas quando alinhadas aos ensinamentos de Paulo Freire nas temáticas que tangem à discriminação e à opressão das minorias.

\section{RESULTADOS E DISCUSSÃO}

\subsection{0 mapeamento da produção}

A busca pela produção de conhecimento apresentou um número significativo de estudos encontrados nas três bases de dados pesquisadas, totalizando 423. Esse número reflete a influência de Paulo Freire no cenário acadêmico mundial. Freire "[...] é o autor na Educação com o maior número de citações em todo o mundo e seu nome tem sido usado para identificar instituições escolares, centros de pesquisas, programas sociais e ONGs em mais de 45 países" (FISCHMAN, 2011, p. 262).

Entretanto, ao identificar apenas 19 artigos que atenderam aos critérios estabelecidos, sendo apenas dois relacionados diretamente com o ensino da EF como componente do currículo escolar, pudemos perceber que a relação entre a teoria freireana e a EF não é fortemente marcada. Em 12 artigos, as práticas corporais tornaram-se temáticas em revistas de áreas socioculturais, sendo assim também alvo de reflexões realizadas por pesquisadores de outras áreas acadêmicas, sendo um deles no contexto da EF Escolar. 
Quadro 1 - Publicações em revistas de áreas diversas

\begin{tabular}{|c|c|}
\hline Cenários e contextos & Estudos \\
\hline Escola do Movimento dos Trabalhadores sem Terra. & Tarlau (2013). \\
\hline Ensino de jovens e adultos. & Connolly; Hussey (2013). \\
\hline Formação profissional. & $\begin{array}{c}\text { McDermott; Shelton; Mogge (2012); } \\
\text { Schwarz-Franco (2016). }\end{array}$ \\
\hline Universo universitário americano & Barbatis (2008). \\
\hline O discurso de um programa de TV & Barros, et al. (2015). \\
\hline Comunidade ribeirinha na Amazônia brasileira. & Reis et al. (2012). \\
\hline Atividades pedagógicas no ambiente escolar. & $\begin{array}{r}\text { Reynolds (2002); Hickling-Hudson (2013); Armitage } \\
(2013) ; \text { Agbenyega; Klibthong (2013) }\end{array}$ \\
\hline Educação Física Escolar & Silva; Francisco (2012). \\
\hline
\end{tabular}

Fonte: Os autores

Apenas sete estudos foram publicados em revistas da EF. Sendo elas:

Quadro 2 - Publicações em revistas específicas da Educação Física.

\begin{tabular}{|c|c|}
\hline Revistas & Estudos \\
\hline Motrivivência & Ventorim (2000). \\
\hline Movimento & Correia; Miranda; Velardi (2011) \\
\hline Physical Education and Sport Pedagogy & Spaaij; Jeanes (2013); Matta; Richards; Hemphill (2015). \\
\hline Revista Mackenzie de Educação Física e Esporte & Casco (2009). \\
\hline Sport, Education and Society & Mwaanga; Prince (2016); Luguetti et al. (2017). \\
\hline
\end{tabular}

Fonte: Os autores

Dos textos encontrados nas revistas específicas da $\mathrm{EF}$, seis estudos tiveram como contexto programas de práticas corporais em ambientes não formais de ensino, e apenas um tinha como contexto de estudo a EF Escolar (VENTORIM, 2000). Dessa forma, entre os 19 artigos encontrados, Silva e Francisco (2012) e Venturim (2000) foram os dois únicos estudos que investigaram o ensino da EF na escola e que utilizam a teoria freireana como seu referencial. Entendemos que o reduzido número de estudos encontrados nas bases de dados escolhidas é um indício de que a pesquisa na área ainda não se apropria de forma profunda e consistente da teoria elaborada por Paulo Freire.

Podemos pensar em algumas hipóteses para explicar o resultado obtido. A constituiç̧ão acadêmica da EF e a política de desenvolvimento científico que vem sendo adotada mundialmente e se reflete na universidade brasileira podem ter impacto no reduzido número de estudos encontrados. Porém, também é possível encontrar outros fatores, não específicos da $\mathrm{EF}$, que também se relacionam com a forma como Paulo Freire tem influenciado a produção do conhecimento na área.

Historicamente, a EF tem se constituído como uma prática social e como uma área do conhecimento intensamente influenciada pelas Ciências Biomédicas. As consequências dessa influência na política científica adotada têm sido exaustivamente discutidas por inúmeros autores, como Job, Fraga e Molina Neto (2008), Manoel e Carvalho (2011), Bracht (2017) e Bossle e Bossle (2018). Um dos aspectos destacados nessa discussão é o olhar privilegiado que recebem os estudos da área biodinâmica, o que não é uma exclusividade da EF brasileira 
(MANOEL; CARVALHO, 2011). Por conseguinte, há uma tendência a valorizar a pesquisa quantitativa, em detrimento dos estudos qualitativos ou interpretativos, predominantes nas áreas sociocultural e pedagógica.

Reflexos dessa política podem ser percebidos na pesquisa aqui apresentada. Assim, identificamos que a discussão realizada pelos autores da área não tem utilizado a teoria freireana para analisar diretamente questões sociais manifestas nas práticas corporais. Um bom exemplo disso é o artigo produzido por Gomes e Duarte (2012), que analisaram a efetividade de um programa de saúde em Florianópolis/SC e para isso utilizaram-se de argumentações freireanas, mas com foco em questões biológicas. Ratifica-se que essa é a referência mais recente, encontrada nas buscas, que abordava Paulo Freire em uma visão biologicista do tema e caberia aqui como exemplo dessa problemática.

Reflexos desta política têm sido sentidos fortemente na pesquisa sobre o ensino da EF na escola. Em 2002, Bossle denunciava que

[...] grande parte da produção científica da área se desenvolve em temas que abrangem o movimento humano por um viés de estudo biomecânico, cinesiológico, fisiológico, postural, em detrimento dos estudos que abordem questões da relação entre o professor de educação física e a escola (BOSSLE, 2002, p. 35).

Como explicitado por Bracht (2017) e Job, Fraga e Molina Neto (2008), a produção de conhecimento na EF, que busca a reflexão sobre a intervenção na prática cotidiana nas escolas, não tem grande espaço nos periódicos da área. Bossle e Bossle (2018) evidenciam que apenas $10 \%$ das dissertações e teses produzidas no programa de Pós-Graduação em Ciência do Movimento Humano da UFRGS apresentam a EF Escolar como tema central. Ao analisar a realidade da EF americana, Manoel e Carvalho (2011, p. 400) afirmam que "as investigações que privilegiam questões socioculturais e pedagógicas têm perdido espaço no campo acadêmico". O fato de encontrarmos apenas dois artigos sobre o ensino da EF na escola pode estar relacionado com essa realidade.

Mas a estrutura acadêmica pode não ser o único fator a influenciar a presença de Paulo Freire na produção do conhecimento na EF. Outro aspecto que pode ter conexão com os resultados obtidos é apresentado por Freitas e Forster (2016). As autoras explicam que é frequente 0 entendimento de que a obra de Paulo Freire tem especial contribuição para investigações sobre a educação de jovens e adultos, uma vez que a prática pedagógica do educador se tornou mais notória com este público. Essa crença pode levar a uma menor utilização de seus textos em pesquisas realizadas no ensino regular. É possível que essa visão limitada da obra de Paulo Freire, como alerta Gadotti (1996), possa também impactar na investigação pedagógica realizada pela EF.

Além disso, o pequeno número de estudos que utilizam a teoria freireana parece não ser exclusividade da EF. Viveiro et al. (2015) investigaram como a obra de Paulo Freire tem sido utilizada em pesquisas sobre o ensino de ciências. Assim como acontece no estudo que ora apresentamos, os autores também encontraram um número reduzido de trabalhos fundamentados no educador brasileiro. Outras pesquisas, que analisaram como a obra de Paulo Freire tem influenciado a produção de conhecimento em diferentes áreas, identificaram que há formas diversas de apropriação dos conceitos elaborados por ele (GERBASI, 2013; ZAIUTH, 2013; ZAIUTH; HAYASHI, 2014). Acreditamos que esta forma de apropriação também pode estar relacionada com o reduzido número de estudos que encontramos nesta pesquisa. 
Para identificar as formas como os pesquisadores que investigam na área de Ciência, Tecnologia e Sociedade se apropriam das obras de Paulo Freire, Zaiuth e Hayashi (2014) e Zaiuth (2013) tomam como base as categorias de apropriação apresentadas por Catani, Catani e Pereira (2001): incidental, conceitual tópica e do modo de trabalho. As autoras constataram que a apropriação incidental está presente em diversos artigos encontrados, sendo a obra de Paulo Freire pouco explorada. Assim, livros como Pedagogia do Oprimido e Pedagogia da Autonomia são citados ao lado de outros autores, sem uma análise aprofundada.

Com base nos resultados apresentados por Medeiros e Godoy (2009), acreditamos que essa forma de apropriação também pode estar presente nos estudos que utilizam a obra de Paulo Freire para compreender a EF e as práticas corporais. Em seu estudo, as autoras analisaram a maneira como os escritos de Bourdieu e de Elias têm sido referenciados em artigos publicados na Revista Brasileira de Ciências do Esporte. Elas identificaram uma apropriação que pode ser considerada incidental, uma vez que o referencial escolhido é frequentemente empregado de forma compartimentada e restrita, com a apresentação de trechos ou ideias isoladas, "[...] muitas vezes transformando o autor numa espécie de ícone para servir como argumento de autoridade" (MEDEIROS; GODOY, 2009, p. 203). A consequência desta forma de apropriação pode ser a criação de releituras deformadas e incoerentes.

Em nossa investigação, optamos por evitar a seleção de artigos que se apropriassem incidentalmente da teoria freireana, ao realizar a busca direta dos descritores (GERBASI, 2013), que deveriam aparecer nos títulos, resumos ou palavras-chave dos artigos. Ainda que esta opção possa ter influenciado a identificação de um número de estudos, permitiu selecionar obras que trazem um olhar mais aprofundado sobre os conceitos discutidos por Paulo Freire.

Assim, nossa intenção foi capturar trabalhos que selecionassem Freire como uma das principais referências e nos possibilitou encontrar, nos 19 artigos selecionados, alinhamentos com os objetivos do estudo e que puderam auxiliar em nossas reflexões, mostrando-nos que por mais que a discrepância numérica exista ou que o espaço para a discussão pedagógica na EF seja reduzido (CAPARROZ; BRACHT, 2007), Paulo Freire vem sendo alicerce de problemáticas que envolvem as práticas corporais em estudos realizados por autores da EF e/ou de outras áreas do conhecimento (LUGUETTI et at., 2017), como analisaremos mais detalhadamente a seguir.

\subsubsection{Práticas corporais tematizadas}

Nos 19 artigos selecionados encontramos alinhamentos com os objetivos do estudo e que puderam auxiliar em nossas reflexões, mostrando-nos que por mais que a discrepância numérica exista ou que o espaço para a discussão pedagógica na EF seja reduzido (CAPARROZ; BRACHT, 2007), Paulo Freire vem sendo alicerce de problemáticas que envolvem as práticas corporais em estudos realizados por autores da EF e/ou de outras áreas do conhecimento (LUGUETTI et al., 2017).

A maioria das publicações encontradas teve a realidade brasileira como objeto de análise com dez estudos desenvolvidos no contexto nacional, ao passo que Estados Unidos, Austrália, África do Sul, Irlanda, Israel, Jamaica, Nova Zelândia, Vietnã e Zâmbia foram fontes de análises para um estudo realizado em cada um desses países. 
Ressalta-se também uma maior concentração de trabalhos encontrados a partir de 2010. Resultado semelhante foi encontrado por Maldonado, Silva e Miranda (2014), ao investigarem publicações relacionadas com o cotidiano escolar da EF. Segundo os autores, este fato está relacionado ao aumento no número de edições das revistas e a um número maior de estudos que são divulgados.

Atentamo-nos, nesse momento da análise, a também entender como as práticas corporais vêm sendo tematizadas por esses estudos:

Quadro 3 - Problematizações das práticas corporais.

\begin{tabular}{|l|l|l|}
\hline Práticas Corporais & \multicolumn{1}{|c|}{ Problematizações } & \multicolumn{1}{|c|}{ Estudos } \\
\hline Jogos e Brincadeiras. & $\begin{array}{l}\text { Visibilidade para culturas diversas; acolhimento } \\
\text { às crianças refugiadas de países em guerra; } \\
\text { valorização da cultura popular. }\end{array}$ & $\begin{array}{l}\text { Reynolds (2002); Casco (2009); } \\
\text { Agbenyega; Klibthong (2013); } \\
\text { Reis et al. (2012); Armitage } \\
\text { (2013). }\end{array}$ \\
\hline Lutas & $\begin{array}{l}\text { Empoderamento estudantil; estratégias de ensino } \\
\text { participativo; questões de preconceito e opressão. }\end{array}$ & $\begin{array}{l}\text { Barbatis (2008); Hickling- } \\
\text { Hudson (2013); Tarlau (2013); } \\
\text { Schwarz-Franco (2016). }\end{array}$ \\
\hline Ginástica & $\begin{array}{l}\text { Análise crítica do discurso midiático em } \\
\text { programa de TV; desenvolvimento da autonomia; } \\
\text { empoderamento de minorias. }\end{array}$ & $\begin{array}{l}\text { Reynolds (2002); Correia, } \\
\text { Miranda; Velardi (2011); Barros } \\
\text { et al. (2015); Schwarz-Franco } \\
\text { (2016). }\end{array}$ \\
\hline Danças & $\begin{array}{l}\text { Acolhimento a imigrantes; meditação no } \\
\text { desenvolvimento da autonomia na tematização } \\
\text { das danças. }\end{array}$ & $\begin{array}{l}\text { Reynolds (2002); McDermott, } \\
\text { Shelton; Mogge (2012); } \\
\text { Hickling-Hudson (2013). }\end{array}$ \\
\hline Esportes & $\begin{array}{l}\text { Questões de preconceito e opressão; racismo; } \\
\text { educação dialógica; desenvolvimento de } \\
\text { senso crítico; luta de classes; Ditadura Militar; } \\
\text { consciência política e reflexão crítica. }\end{array}$ & $\begin{array}{l}\text { Ventorim (2000); Barbatis } \\
\text { (2008); Mwaanga e Prince } \\
\text { (2016); Spaaija e Jeanes, } \\
\text { (2013); Connolly e Hussey } \\
\text { (2013); Mattaa; Richards; } \\
\text { Hemphill (2015); Luguetti et. al. } \\
\text { (2017). }\end{array}$ \\
\hline
\end{tabular}

Fonte: Os autores

Sabe-se que a diversificação das práticas corporais com que os seres humanos têm contato durante suas experiências de vida é importante para que eles atribuam sentidos e significados a elas (BETTI, 2015). Por isso, faz-se importante salientar que percebemos discussões que atravessaram as diversas práticas corporais nos estudos analisados.

A esse respeito, Neira (2016) nos explica que reconstruímos na EF as ideias de Paulo Freire, no entendimento de que as práticas corporais precisam ser problematizadas pelos professores em suas aulas, a partir da tematização do futebol, do congado ou do skate, por exemplo. Logo, problematizar é desnaturalizar, provocar, fazer refletir sobre aquilo que, por vezes, fazemos no automático. Esse movimento acontece na EF a partir da tematização, ou seja, a partir de atividades pedagógicas que permitam aos alunos e às alunas abordar as práticas corporais pela vivência, experimentação, diálogo e reflexão, proporcionando que os estudantes situem as danças, lutas, ginásticas, esportes, jogos, brincadeiras, atividades rítmicas expressivas em seus contextos culturais. 


\subsection{Categorias freireanas e discussões na educação física: a organização da síntese}

\subsubsection{Consciência}

Tema constante nas obras de Paulo Freire, ratificamos a valorização da conscientização percebida durante a leitura dos textos analisados. Nos estudos, foi latente a preocupação dos autores com relação à tomada de consciência acerca das práticas corporais entrelaçadas aos contextos sociais. Essa explicação, de acordo com o nosso entendimento, caminha no sentido de que o método de ensino dialógico difundido por Paulo Freire é também conhecido como Método da Consciência (LOPES; MACEDO, 2011).

Outro ponto marcante na leitura dos artigos foi o fato de que a tomada de consciência se dá, em grande parte, alicerçada em questionamentos políticos, como evidenciado por Tarlau (2013); Connolly e Hussey (2013) e Luguetti et al. (2017). Assim, parece-nos óbvio entender por que, durante toda a sua obra, Paulo Freire defende que não há como separar a Política da Educação, ensinando-nos que toda prática pedagógica é também política, sendo, portanto, incabível acreditar na existência de qualquer tipo de neutralidade pedagógica.

A influência do discurso midiático e os interesses forjados em uma sociedade capitalista também são apontados como elementos importantes em uma prática pedagógica que vise à emancipação dos sujeitos (BARROS et al., 2015; SCHWARZ-FRANCO, 2016).

A esse respeito, os estudos se aproximam dos entendimentos de Medina (1987), que, alicerçado na obra de Paulo Freire para construir suas reflexões sobre a temática da EF e consciência, defende que, para melhorar sua qualidade de vida, um indivíduo "deve objetivar os níveis mais altos de consciência, a fim de transformar o injusto e o desumano que the afetam" (p.30). Não basta apenas assumir a prática das atividades físicas, mas, sim, questionálas em um movimento de reflexão sobre elas. Ao escrever sobre as limitações de uma EF que garanta os cuidados do corpo, o autor advoga em favor de uma tomada de consciência crítica pelos professores da disciplina.

Também influenciada por Paulo Freire, a concepção de ensino Crítica Emancipatória, defendida por Kunz (1994), evidencia mudanças na perspectiva do esporte de rendimento, indica a crítica, a reelaboração e a transformação dos princípios do esporte que, precipitadamente, têm sido adaptados nas aulas de EF, refletindo-se em uma prática seletiva, discriminadora e dominadora, opostas à conscientização, tão valorada na obra freireana (BRACHT, 1999; VENTORIM, 2000).

\subsubsection{Cultura popular}

Como elucidação dos ensinamentos de Paulo Freire acerca da valorização da cultura popular, Reis et al. (2002) analisaram as brincadeiras de uma comunidade ribeirinha da Amazônia, mostrando-nos sua inserção em um contexto social mais amplo. Nesse estudo, seus autores constataram, à luz de obra de Paulo Freire, que as brincadeiras expressavam uma cultura tipicamente ribeirinha, influenciadas pela fauna e flora, representando temas domésticos e aspectos ligados ao meio de subsistência. Nota-se que o contato entre os habitantes da comunidade, a interação familiar e a cultura infantil apresentam-se ativos, criando estratégias de encontros sociais capazes de transmitir e modificar a cultura desse povo, em diversos espaços, dentre eles a escola. 
A esse respeito foram também observados estudos que tratavam do acolhimento a imigrantes que por diferentes motivos deixaram seus países. Nesses artigos, as práticas corporais puderam ser usadas como instrumentos capazes de fazer com que as culturas de origem das crianças não fossem suprimidas, pelo menos por completo, ao embarcarem em um novo contexto social (AGBENYEGA; KLIBTHONG, 2013; MCDERMOTT; SHELTON; MOGGE, 2012).

Enfatizamos, assim, como as discussões acerca da cultura popular são traços marcantes nas obras encontradas. Nesse sentido, concordamos com Peroza (2012) que, em se tratando da relação da cultura popular com Paulo Freire, o "corpo" do educando é também "síntese cultural" da realidade em que se encontra, portanto, objeto de interpretação e transformação e, ao mesmo tempo, sujeito que interpreta e transforma, cria e recria o mundo.

Ao trazermos as discussões para a EF Escolar, salientamos nos Estudos Culturais aproximações com as ideias relativas à discussão de diversas culturas e às manifestações corporais. Neira e Nunes (2009), ao defenderem uma prática pedagógica alicerçada no Multiculturalismo Crítico, argumentam sobre a necessidade de que as tematizações e as discussões acerca das práticas corporais sejam flexibilizadas de acordo com o contexto social dos estudantes, fazendo com que o relacionamento de diversas culturas no ambiente escolar sejam objeto das aulas de EF.

Nesse sentindo, os professores precisam fazer com que os estudantes se sintam representados nas aulas, através das diversas práticas corporais tematizadas na $\mathrm{EF}$, a fim de que alcancem uma verdadeira justiça curricular, contrapondo temas como capoeira, congado, maculelê, jogos indígenas, funk, hip hop aos tradicionais esportes coletivos (voleibol, handebol, basquetebol e futebol) de origem nórdica, branca, elitizada, heterossexual e masculina (NEIRA; NUNES, 2009; FRANÇOSO; NEIRA, 2014).

\subsubsection{Empoderamento}

Alinhando-se às ideias de Paulo Freire acerca do conceito, por ele perpetuado, de empoderamento, Connolly e Hussey (2013) analisam o papel da educação de adultos para a formação de uma democracia crítica. As reflexões se dão no enfrentamento ao sofrimento social que esses autores perceberam durante o trabalho realizado como educadores do público adulto. McDermott, Shelton e Mogge (2012) relataram em seu estudo a construção de oficinas de leitura e de práticas corporais como a dança, a mímica e a interpretação. O objetivo das oficinas era buscar o empoderamento de imigrantes, a partir de problematizações realizadas pelos educadores que visavam, a partir da práxis de Paulo Freire, ao desenvolvimento crítico dos sujeitos do processo.

Barbatis (2008) baseou o seu projeto de pesquisa em uma abordagem de estudo de caso para entender as experiências de estudantes de universidades americanas. No estudo, percebeu-se como o ingresso em times de basquete das equipes universitárias foi estratégia de enfretamento ao racismo e ao preconceito sofrido pelos atletas negros.

Mwaanga e Prince (2016), por sua vez, relatam as experiências de um projeto social de esportes para meninas na Zâmbia que visa, através da prática dialógica proposta por Paulo Freire, ao empoderamento feminino. Durante o texto, questões como o alto índice de doenças que acometem as mulheres, bem como a violência contra elas, são abordadas. 
Esses estudos se aproximam das ideias de Bracht (1999) de que, para entender as necessidades do contexto escolar, precisamos de trabalhos pedagógicos organizados para que a EF possa contribuir com os conteúdos que podem ser trabalhados associados aos aspectos históricos. Aspectos esses que envolvem manifestações, desencadeando discussões sobre temas como violência, gênero, racismo, desigualdade social, preconceito a cultura e tradições de determinado lugar.

\section{CONSIDERAÇÕES FINAIS}

Diante da relevante contribuição da obra de Paulo Freire para a produção científica em diferentes áreas do conhecimento, realizamos o presente estudo com o propósito de entender como a teoria freireana vem sendo estudada pela comunidade acadêmica da EF. O levantamento realizado nas bases de dados permitiu a identificação de apenas 19 artigos científicos nacionais e internacionais, sendo dois deles realizados no contexto da EF Escolar. Dessa forma, esse pequeno número de estudos encontrados pode ser considerado um indício de que a pesquisa na área ainda não tem sido capaz de utilizar a teoria elaborada por Paulo Freire de forma profunda e consistente. Este resultado pode estar relacionado com 0 desprestígio da pesquisa nas áreas sociocultural e pedagógica da EF e com forma como os pesquisadores da área tem percebido e se apropriado da obra do autor.

Contudo, embora o número de estudos encontrados tenha sido pequeno, foi possível perceber que a teoria freireana vem subsidiando a investigação sobre diversas práticas corporais em estudos realizados por autores da EF e/ou de outras áreas do conhecimento. A análise dos estudos permitiu identificar a presença nas obras das três categorias freireanas selecionadas: consciência, cultura popular e empoderamento.

Em concordância com a análise de Bossle (2018), o estudo permitiu constatar que os escritos de Paulo Freire se assumem enquanto alternativa viável para educadores de EF que organizam a sua prática profissional com a intenção de desvelar a sua realidade e produzir uma sociedade mais justa, igualitária e empoderada de conhecimentos para combater a opressão das classes dirigentes em todos os aspectos que envolvem a vida cotidiana.

Embora seja corriqueiro escutarmos que as ideias de Paulo Freire influenciam a prática pedagógica dos docentes de EF que lecionam no ambiente escolar, sentimos uma carência, nos resultados encontrados, de estudos sobre essa temática nas bases de dados pesquisadas. Portanto, sugerimos que os pesquisadores da área se debrucem cada vez mais sobre os escritos de Paulo Freire para que possamos compreender melhor o quanto as suas ideias podem influenciar na formação de um olhar crítico, em tempos tão temerosos, sobre as práticas corporais.

\section{REFERÊNCIAS}

AGBENYEGA, Joseph; KLIBTHONG, Sunanta. Whole school initiative: has inclusive education gone astray? International Journal of Whole Schooling, v. 9, n. 1, p. 3-22, 2013. 
APPLE, Michael; AU, Wayne; GANDIN, Luis Armando. Educação crítica: análise internacional. Porto Alegre: Artmed, 2011.

ARMITAGE, Andrew. Conscientization, dialogue and collaborative problem based learning. Journal of Problem Based Learning in Higher Education, v. 1, n. 1, p. 1-18, 2013.

BARBATIS, Peter. Perceptions of underprepared community college students regarding their educational achievement: Preliminary Analysis of a Pilot Study: secondary title. Miami: Fort Wayne: Conference of the American Educational Research Association, 2008.

BARROS, Lia Bezerra Furtado et al. Contribuição do meio midiático para a promoção da saúde cardiovascular. Revista de cuidado é fundamental online, v. 7, n. 2, p. 2241-2253, 2015.

BETTI, Mauro. Educação física escolar: ensino e pesquisa-ação. ljuí: Unijuí, 2015.

BOSSLE, Fabiano. Nosso "Inédito Viável": professor de educação física intelectual transformador. In: MALDONADO, Daniel Teixeira; NOGUEIRA, Valdilene Aline; FARIAS, Uirá Siqueira. Os professores como Intelectuais: novas perspectivas didático-pedagógicas na Educação Física escolar brasileira. Curitiba: CRV, 2018. p. 19-34.

BOSSLE, Fabiano; BOSSLE, Cibele Biehl. "O conhecimento de quem é mais valioso?" Educação Física Escolar, educação crítica e pesquisa científica no grupo DIMEEF/UFRGS. In: BOSSLE, Fabiano et al. Educação física escolar, etnografias e autoetnografias: a formação de intelectuais transformadores. Curitiba: CRV, 2018. p. 15-32.

BOSSLE, Fabiano. Planejamento de ensino na educação física: uma contribuição ao coletivo docente. Movimento, v. 8, n. 1, p 31-39, 2002.

BRACHT, Valter. A constituição das teorias pedagógicas em educação física. Caderno Cedes, ano 19 , n. 58, p. $69-88,1999$.

BRACHT, Valter. Prefácio. In: NOGUEIRA, Valdilene Aline; FARIAS, Uirá de Siqueira; MALDONADO, Daniel Teixeira. Práticas pedagógicas inovadoras nas aulas de educação física escolar: indícios de mudanças 2. Curitiba: CRV, 2017. p. 11-13.

CAPARROZ, Francisco Eduardo; BRACHT, Valter. O tempo e o lugar de uma didática da educação física. Revista Brasileira de Ciências do Esporte, v. 28, n. 2, p. 21-37, 2007.

CASCO, Patrício. Autonomia, humanização e a formação de professores da prefeitura municipal de São Paulo. Revista Mackenzie de Educação Física e Esporte, v. 8, n. 2, p. 103-110, 2009.

CASTELLANI FILHO, Lino. Educação Física no Brasil: a história que não se conta. São Paulo: Papirus, 1988.

CATANI, Afrânio Mendes; CATANI, Denice Bárbara; PEREIRA, Gilson. As apropriações da obra de Pierre Bourdieu no campo educacional brasileiro, através de periódicos da área. Revista Brasileira de Educação, n. 17, p. 63-85, 2001.

CONNOLLY, Brid; HUSSEY, Peter. The war against people: adult education practice for critical democracy. The Adult Learner: the journal of adult and community education in Ireland, p. 7589, 2013.

CORREIA, Mesaque Silva; MIRANDA, Maria Luiza de Jesus; VELARDI, Marília. A prática da educação física para idosos ancorada na pedagogia freireana: reflexões sobre uma experiência dialógica-problematizadora. Movimento, v. 17, n. 4, p. 281-297, 2011. 
FISCHMAN, Gustavo. A (não) domesticação da pedagogia do oprimido. In: APPLE, Michael; AU, Wayne; GANDIN, Luis Armando. Educação crítica: análise internacional. Porto Alegre: Artmed, 2011. p. 262-284.

FRANÇOSO, Saulo; NEIRA, Marcos Garcia. Contribuições do legado freireano para o currículo da Educação Física. Revista Brasileira de Ciências do Esporte, v. 36, n. 2, p. 531-546, 2014.

FREIRE, Elisabete dos Santos; MIRANDA, Maria Luiza de Jesus. The production of knowledge about the building of values in physical education at school: methods, methodology and epistemology. Physical Education and Sport Pedagogy, v. 19, n. 1, p. 35-47, 2014.

FREIRE, Paulo. Educação como prática da liberdade. Rio de Janeiro: Paz e Terra, 1967.

FREIRE, Paulo. Conscientização e alfabetização: uma nova visão do processo. Revista de Cultura da Universidade do Recife, n. 4, p. 1-15, abr./jun. 1963.

FREIRE, Paulo. Pedagogia do oprimido. 17. ed. Rio de Janeiro: Paz e Terra, 1987.

FREIRE, Paulo. Pedagogia da autonomia: saberes necessários à prática docente. São Paulo: Paz e Terra, 1996.

FREITAS, Ana Lucia Souza; FORSTER, Mari Margarete dos Santos. Paulo Freire na formação de educadores: contribuições para o desenvolvimento de práticas crítico-reflexivas. Educar em Revista, n. 61, p. 55-69, jul./set. 2016.

GADOTTI, Moacir. Paulo Freire: Uma biobibliografia. São Paulo: Cortez, 1996.

GERBASI, Luciana Barbosa. Impacto do pensamento de Paulo Freire nas pesquisas de pós-graduação no Brasil (1987 - 2010). 2013. 146 f. Tese (Doutorado) - Faculdade de Educação, Universidade Estadual de Campinas, Campinas, 2013.

GIL, Antônio Carlos. Como elaborar projetos de pesquisa. São Paulo: Atlas, 2007.

GOMES, Marcius Almeida; DUARTE, Silva Maria de Fátima. Efetividade de uma intervenção de atividade física em adultos atendidos pela estratégia saúde da família: Programa Ação e Saúde Floripa-BRASIL. Revista Brasileira de Atividade Física e Saúde, v. 13, n. 1, p. 44-56, 2012.

HICKLING-HUDSON, Anne. Theatre-Arts pedagogy for social justice: case study of the Area Youth Foundation in Jamaica. Current Issues in Comparative Education, v. 15, n. 2, p. 15-34, 2013.

JOB, Ivone; FRAGA, Alex Branco; MOLINA NETO, Vicente. Invisibilidade das revistas científicas brasileiras de educação física nas bases de dados. Cadernos BAD, v.1, p.14-26, 2008.

KUNZ, Elenor. Transformação didático-pedagógica do esporte. ljuí: UNIJUÍ, 1994.

LEVY, Yair; ELLIS, Timothy. A system approach to conduct an effective literature review in support of information systems research. Informing Science Journal, v.9, p.181-212, 2006.

LOPES, Alice Casimiro; MACEDO, Elisabeth. Teorias de currículo. São Paulo: Cortez, 2011.

LUGUETTI, Carla et al. Exploring an activist approach of working with boys from socially vulnerable backgrounds in a sport context. Sport, Education and Society, v. 22, n. 4, p. 493510, 2017. 
MALDONADO, Daniel Teixeira; SILVA, Sheila Aparecida Pereira dos Santos; MIRANDA, Maria Luiza de Jesus. Pesquisas sobre a educação física no cotidiano da escola: o estado da arte. Movimento, v. 20, n. 4, p. 1373-1395, 2014.

MANOEL, Edison de Jesus; CARVALHO, Yara Maria de. Pós-graduação na educação física brasileira: a atração (fatal) para a biodinâmica. Educação e Pesquisa, v. 37, n. 2, p. 389-406, ago. 2011.

MATTAA, Gylton; RICHARDS, Andrew Richard; HEMPHILL, Michael. Toward an understanding of the democratic reconceptualization of physical education teacher education in post-military Brazil. Physical Education and Sport Pedagogy, v. 20, n. 3, p. 329-345, 2015.

McDERMOTT, Morna; SHELTON, Nancy Rankie; MOGGE, Sthefen G. Preservice teachers' perceptions of immigrants and possibilities of transformative pedagogy: recommendations for a praxis of" critical aesthetics". International Journal of Multicultural Education, v. 14, n. 2, p. 1-22, 2012.

MEDEIROS, Cristina Carta Cardoso; GODOY, Letícia. As referências de Pierre Bourdieu e Norbert Elias na Revista Brasileira de Ciências do Esporte: mapeando tendências de apropriação e de produção de conhecimento na área da Educação Física (1979-2007). Revista Brasileira de Ciências do Esporte, v. 30, p. 199-214, 2009.

MEDINA, João Paulo Subirá. A educação física cuida do corpo e "mente". São Paulo: Papirus, 1987.

MWAANGA, Oscar; PRINCE, Samantha. Negotiating a liberative pedagogy in sport development and peace: understanding consciousness raising through the Go Sisters programme in Zambia. Sport, Education and Society, v. 21, n. 4, p. 588-604, 2016.

NEIRA, Marcos Garcia; NUNES, Mario Luiz Ferrari. Educação Física, Currículo e Cultura. São Paulo: Phorte, 2009.

NEIRA, Marcos Garcia. Educação Física cultural: carta de navegação. Arquivos em Movimento, v. 12, n. 2, p. 80-101, 2016.

PEROZA, Juliano. Reflexões sobre Cultura e Diversidade Cultural em Paulo Freire: Um humanismo crítico para a Transculturalidade em Educação. ANPED SUL, 9, 2012. Disponível em: <http://www.ucs.br/etc/conferencias/index.php/anpedsul/9anpedsul/paper/viewFile/3183/420>. Acesso em: 13 dez. 2018.

REIS, Daniela Castro et al. Brincadeiras em uma comunidade ribeirinha amazônica. Psicologia: teoria e prática, v. 14, n. 3, p. 48-61, 2012.

REYNOLDS, Joan. Thich Nhat Hanh As Adult Educator. Gorham: University of Southern Maine, 2002.

ROCHA, Mayara et al. As teorias curriculares nas produções acerca da Educação Física: uma revisão sistemática. In: CONGRESSO DE CIÊNCIAS DE ESPORTE, 6, 2015; CONGRESSO BRASILEIRO DE CIÊNCIAS DO ESPORTE, 19, 2015, Vitória. Anais do XIX Congresso Brasileiro de Ciências do Esporte. Vitória, 2015. p. 1-15

SALDAÑA, Johnny. Fundamentals of Qualitative Research: understanding qualitative research, New York: Oxford University, 2013. 
SCHWARZ-FRANCO, Orit. Teachers in film: inspiration for autonomous and transformative teaching or a warning against it? Universal Journal of Educational Research, v. 4, n. 5, p. 994-1002, 2016.

SILVA, Sabrina Melo Correia; FRANCISCO, Marcos Vinícius. Educação Física Escolar e autonomia: reflexões sobre as contribuições da teoria histórico-cultural. Colloquium Humanarum, v. 9, n. 2, p. 66-72, 2012.

SOARES, Carmem Lucia et al. Metodologia do ensino de Educação Física. São Paulo: Cortez, 2012.

SPAAIJ, Ramón; JEANES, Ruth. Education for social change? A Freirean critique of sport for development and peace. Physical Education and Sport Pedagogy, v. 18, n. 4, p. 442-457, 2013.

TARLAU, Rebbeca. The social(ist) pedagogies of the MST: towards new relations of production in the Brazilian countryside. Education Policy Analysis Archives, v. 21, n. 41, p. 1-27, 2013.

VALOURA, Laura de Castro. Paulo Freire, o educador brasileiro autor do termo Empoderamento, em seu sentido transformador. 2006. Disponível em: <http://tupi.fisica. ufmg.br/michel/docs/Artigos e textos/Comportamento organizacional/empowerment por paulo frei re.pdf>. Acesso em: 19 fev. 2018.

VENTORIM, Silvana. Caracterização do esporte segundo a orientação didático-pedagógica da teoria de Paulo Freire. Motrivivência, v. 11, n. 14, p. 187-198, 2000.

VIVEIRO, Alessandra Aparecida et al. A apropriação da obra de Paulo Freire na produção científica em ensino de Ciências (2010-2014). In: ENCONTRO NACIONAL DE PESQUISA EM EDUCAÇÃO EM CIÊNCIAS, 10., 2015, Águas de Lindóia. Anais... Águas de Lindóia, 2015.

ZAUITH, Gabriela; HAYASHI, Maria Cristina Piumbato Innocentini. Construção e aplicação de matrizes bibliométrica e epistemológica para análise do referencial freireano no Ensino de Ciências. Filosofia e Educação, v. 6, n. 2, p. 113-145, 2014.

ZAUITH, Gabriella Leite Lopes. 0 referencial teórico de Paulo Freire no ensino de ciências e na educação CTS: um estudo bibliométrico e epistemológico. 2013. 258 f. Tese (Doutorado em Educação) - São Carlos: Universidade Federal de São Carlos, 2013.

Apoio:

O presente trabalho foi realizado com apoio da Coordenação de Aperfeiçoamento de Pessoal de Nível Superior - Brasil (CAPES) - Código de Financiamento 001. This study was financed in part by the Coordenação de Aperfeiçoamento de Pessoal de Nível Superior - Brasil (CAPES) Finance Code 001. 